\title{
ALB: um espaço praticado ${ }^{1}$
}

\section{ALB: an experienced space}

https://doi.org/10.34112/2317-0972a2020V38n79p123-129

Norma Sandra de Almeida Ferreira ${ }^{2}$

Quem PRoCURA PELA AsSociaÇão de LeItURA Do BRASIL - ALB - depara-se com uma sala no $1^{\circ}$ piso do anexo II da FE, na Unicamp. Quem a acha, se espanta com o espaço reduzido - $30 \mathrm{~m}^{2}$ - a sediar uma instituição que conquistou, ao longo de sua existência, projeção e reconhecimento nacional não só pelo quadro diversificado de associados que se espalha pelo país, mas, sobretudo, pela sua história de luta, de envolvimento, de proposições e ações em prol do acesso, convívio, posse dos objetos e gestos ligados ao mundo da leitura e da escrita, como opção política de não exclusão da grande população brasileira no âmbito das ações leitoras. Podese, até mesmo, parodiar a questão tema deste $18^{\circ}$ COLE: "A ALB grita. Escuta?".

Sua sede não foi sempre ali. Antes disso esteve locada em sala de docentes ligados ao departamento de Metodologia de Ensino da FE, ainda no prédio do Ciclo Básico/Unicamp.

Mas é na sala que ela ocupa hoje, em um dos prédios da FE, que passei muitas e longas horas, desde 2002, como membro da Diretoria. Na maioria das vezes, estive acompanhada de outras pessoas que, mais ou menos envolvidas em cargos

1. Texto apresentado pela autora na mesa redonda "Sentidos da ALB" durante o $18^{\circ}$ CONGRESSO DE LEITURA DO BRASIL: “O mundo grita. Escuta?”, em 17 de julho de 2012, Unicamp, Campinas, SP.

2. Professora da Faculdade de Educação - Unicamp. Atuou como membro da Diretoria da ALB, $1^{\mathrm{a}}$ ou $2^{\mathrm{a}}$ secretária (2002-2009) e presidenta (2009-2010). 
da diretoria da entidade, colaboraram para que esta desempenhasse seu papel e função. É esta sala que ocupa minha fala e a partir da qual proponho um itinerário. Alguns espaços físicos são presença em nossas memórias, constituindo-se em memórias de nós mesmos que neles habitamos.

Em tempos virtuais, nos quais o espaço familiar e o profissional parecem entrecruzados e indissociáveis por se limitarem, em grande parte, a um lugar em que cabe uma tela/teclado (cada vez menores), se abrindo para o mundo de forma simultânea e acelerada (skype, e-mail, facebook etc.), pode parecer anacrônico que a memória de nossa geração ainda seja habitada por lugares físicos a serem transpostos através de corredores, escadas, portas, janelas, paredes: uma sede, a da ALB.

Sua entrada é pela parte de trás do Anexo 2 da FE. Subindo o primeiro lance de escada e já no hall, dirigindo o olhar para a direita o visitante encontrará a identificação na porta: Associação de Leitura do Brasil.

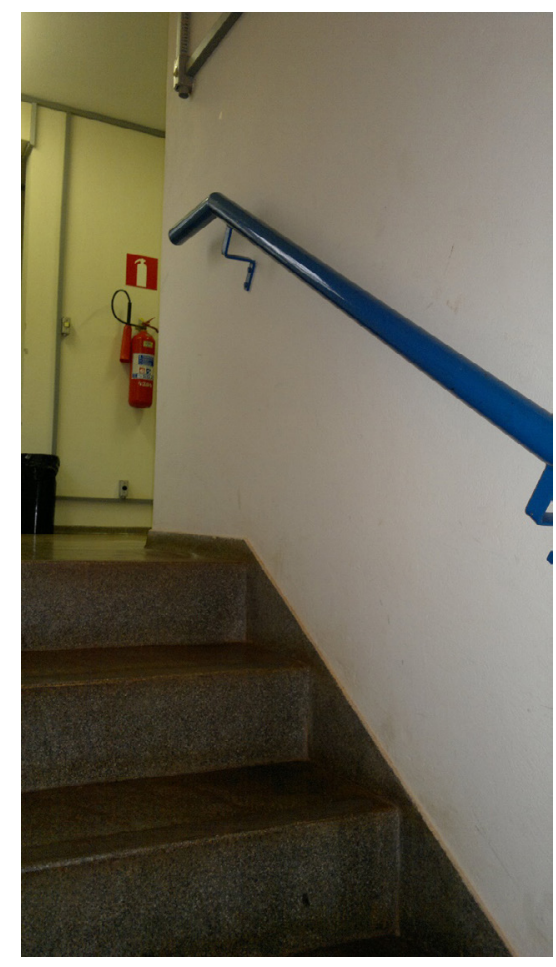

Fotografia 1 - Entrada do Anexo II da FE/ Unicamp

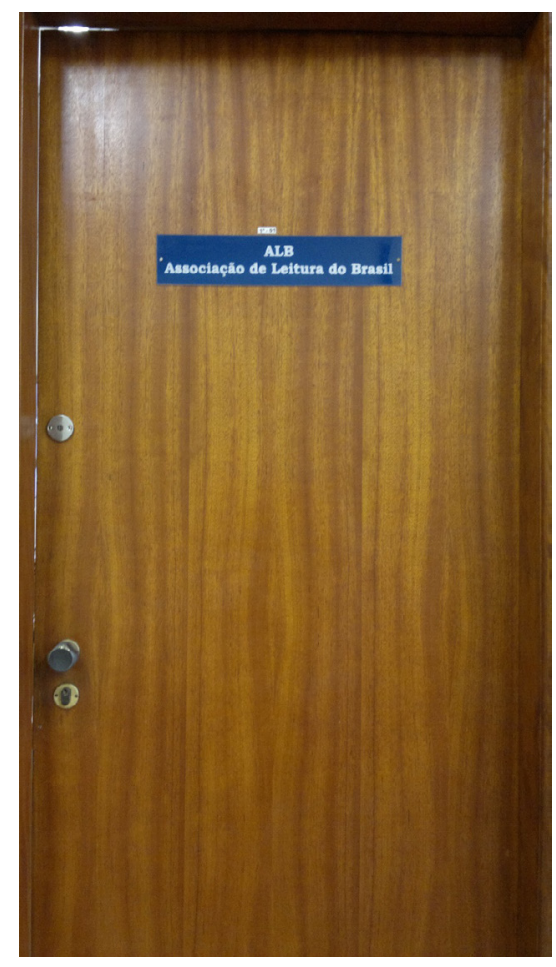

Fotografia 2 - Entrada da ALB 
No mesmo hall, se vê à frente, uma porta indicada como sendo do CEDES uma entidade que, como a ALB, promove e divulga estudos ligados ao campo da educação, e que também foi criada nos anos 80 . Tempos de sonhos e de luta.

Quando se abre a porta da ALB, tem-se a visão do espaço da secretaria, que é "decorado" com duas mesas, dois computadores, uma impressora e um aparelho de fax, um telefone e armários-balcão que guardam documentos mais atuais ligados ao funcionamento burocrático e institucional da entidade. Em cima destes balcões, o que me chama mais a atenção são os últimos lançamentos de livros e da revista LTP, publicados pela ALB.

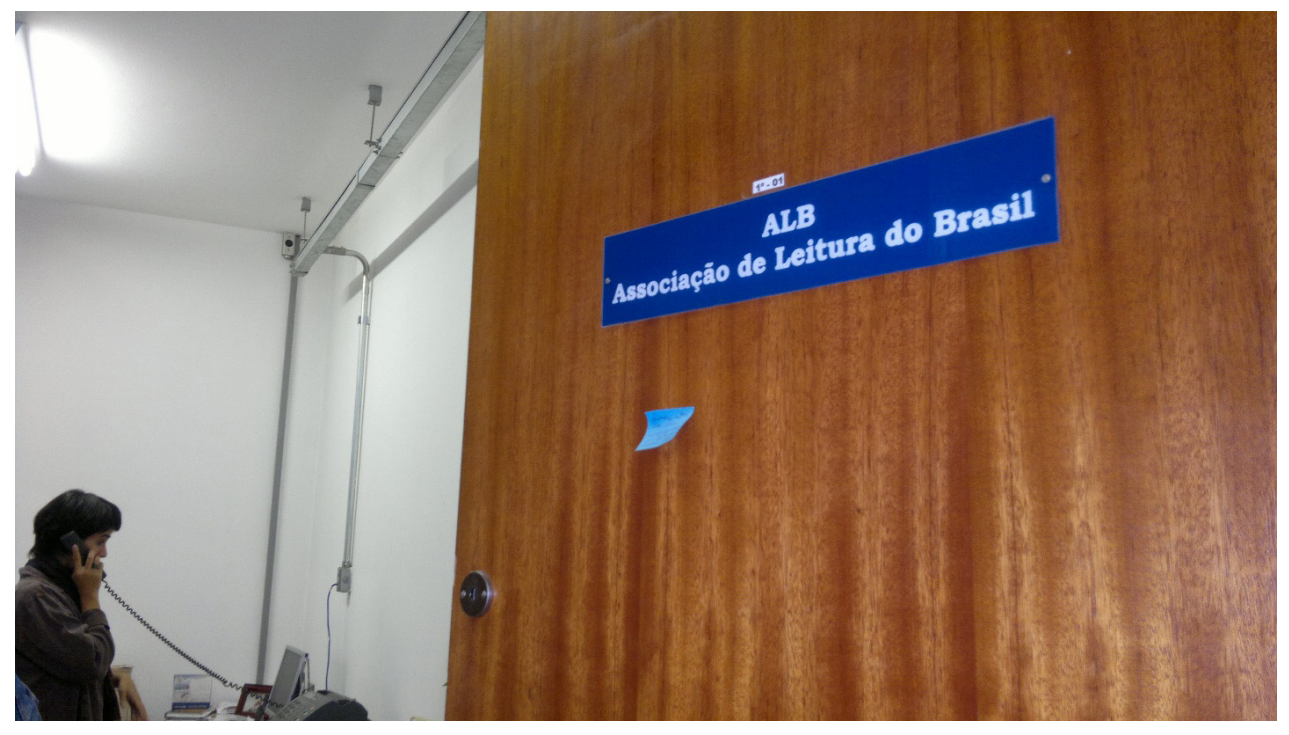

Fotografia 3 - Espaço da secretaria da ALB

Nesta "sala da secretaria", a oscilação de temperatura "castiga" as pessoas que lá ficam por muitas horas seguidas. No inverno, o piso frio exige um aquecedor de chão; no verão, o ventilador ou o ar condicionado funcionam o tempo todo. Temperaturas que também oscilam metaforicamente, conforme as fases que a entidade atravessa: preparação de ações e iniciativas como os COLEs, Seminário Nacional do Jornal, Fórum Desafios do Magistério; edição e distribuição de suas revistas: Leitura: Teoria \& Prática - LTP, Linha Mestra - LM. Temperaturas que também oscilam, metaforicamente, inclusive por causa de sua infraestrutura bastante simples: um grupo pequeno de 
executores mais diretamente envolvidos com a iniciativa de arquitetar e promover essas ações e do funcionamento ainda não completamente informatizado e on-line.

Sons se intensificam ou se espaçam neste lugar: dos carimbos nos envelopes e ofícios; do telefone, da impressora e do fax; dos passos e cumprimentos de colegas do grupo de pesquisa que descem do andar de cima; do digitar no teclado; da máquina que corta o gramado em frente; do gerador da FE, da tosse de alguém. Sons que envolvem vida e trabalho em tempos compreensíveis e perturbadores de nossa memória.

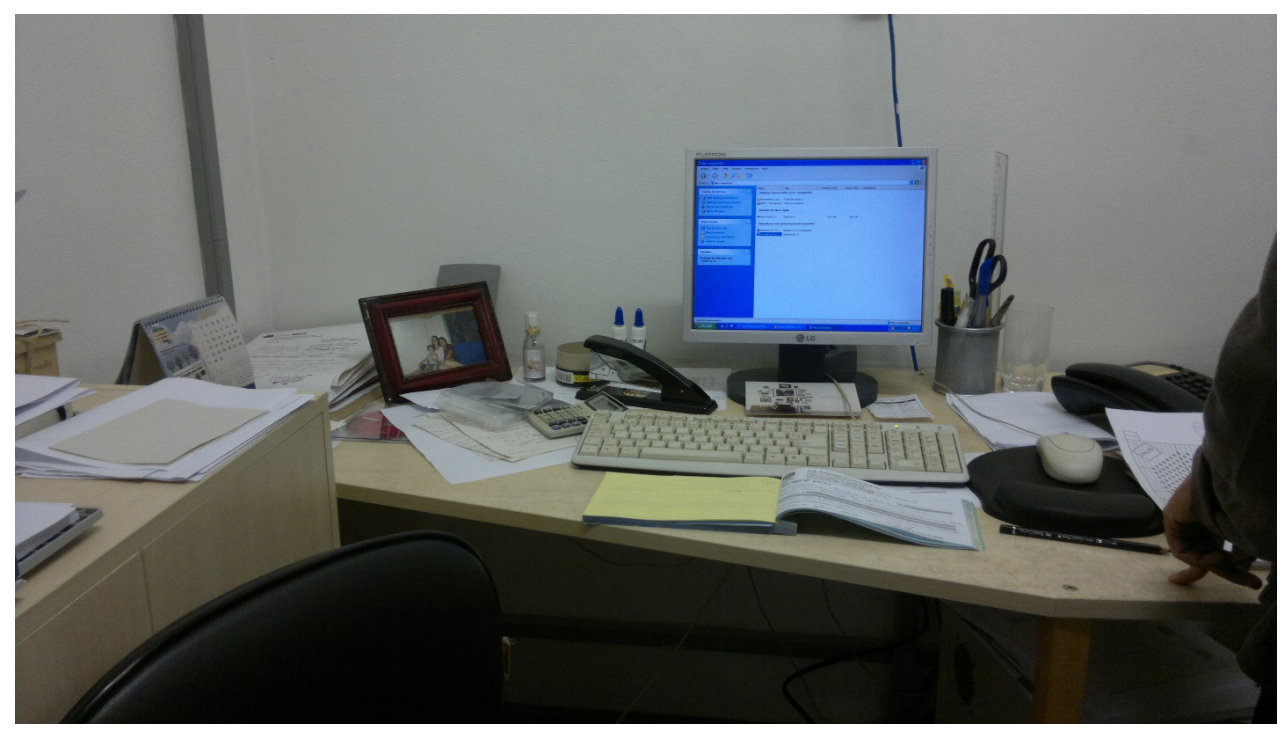

Fotografia 4 - Mesa da secretaria

A mesa da "secretaria" sugere as urgências e importância do que há a se resolver: bloco aberto de recibos de pagamentos, assim como aberta a tela do computador; tesouras, fita crepe, colas, folhas e folhas com anotações se derramam da mesa para a parte de cima do armário-balcão, folhas-impressões de fax - objetos de uma sociedade escriturística movimentados pelos seis membros da diretoria, por duas secretárias, por cerca de duzentos associados, milhares de participantes em eventos, mais de duzentos mil acessos on-line no site. Nessa mesa, um porta-retrato com fotos de familiares humaniza o espaço. Uma calculadora e um calendário sugerem busca de controle do tempo, do espaço, das finanças? 
Uma divisão - de madeira - separa a parte da "secretaria" da "sala de reuniões". A disposição dos móveis sugere gestos, ações, relações. Essa sala é rodeada de armários (dois deles até o teto e os outros dois em forma de balcão) e uma mesa com mais um computador. No centro da sala, uma grande mesa - de madeira, rústica, retangular - ocupa lugar de destaque.

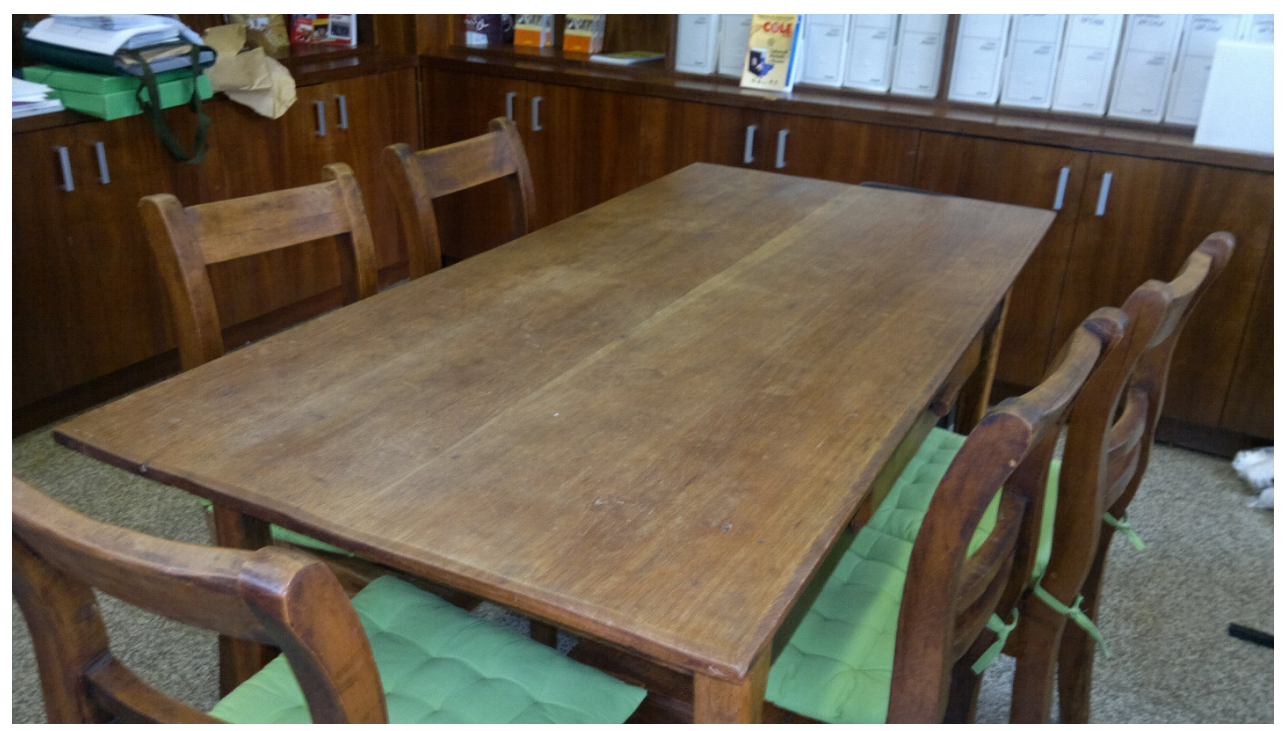

Fotografia 5 - Sala de reuniões da ALB

A mesa.É ela que, inerte e muda, participa silenciosamente, aguarda as reuniões, às vezes mais, às vezes menos difíceis, densas, reunindo pessoas que trabalham nos "bastidores", prestando serviços voluntários ou comerciais (prestadores de serviços) à entidade. Em volta dela, já se sentaram várias diretorias e conselhos editoriais das revistas Leitura: Teoria e Prática e Linha Mestra, vários parceiros (editores, jornalistas, pessoas envolvidas em outras instituições e associações); contadores que cuidam das finanças; fornecedores de material (confecção de camisetas, canetas, pastas); profissionais responsáveis pela elaboração dos sites ou pela produção dos anais dos eventos; pessoas que dão suporte técnico (gravações, coffee-break, passagens aéreas e hospedagens de convidados dos eventos) etc. Em volta dela, são definidos os encaminhamentos e as decisões ligadas à atuação da entidade, que preparam os instantes posteriores de inserção de informações, de registro digital 
da história dessa entidade, de elaboração dos projetos de solicitação de financiamentos junto às agencias de fomento, de articulação em novas parcerias com outras associações e instituições.

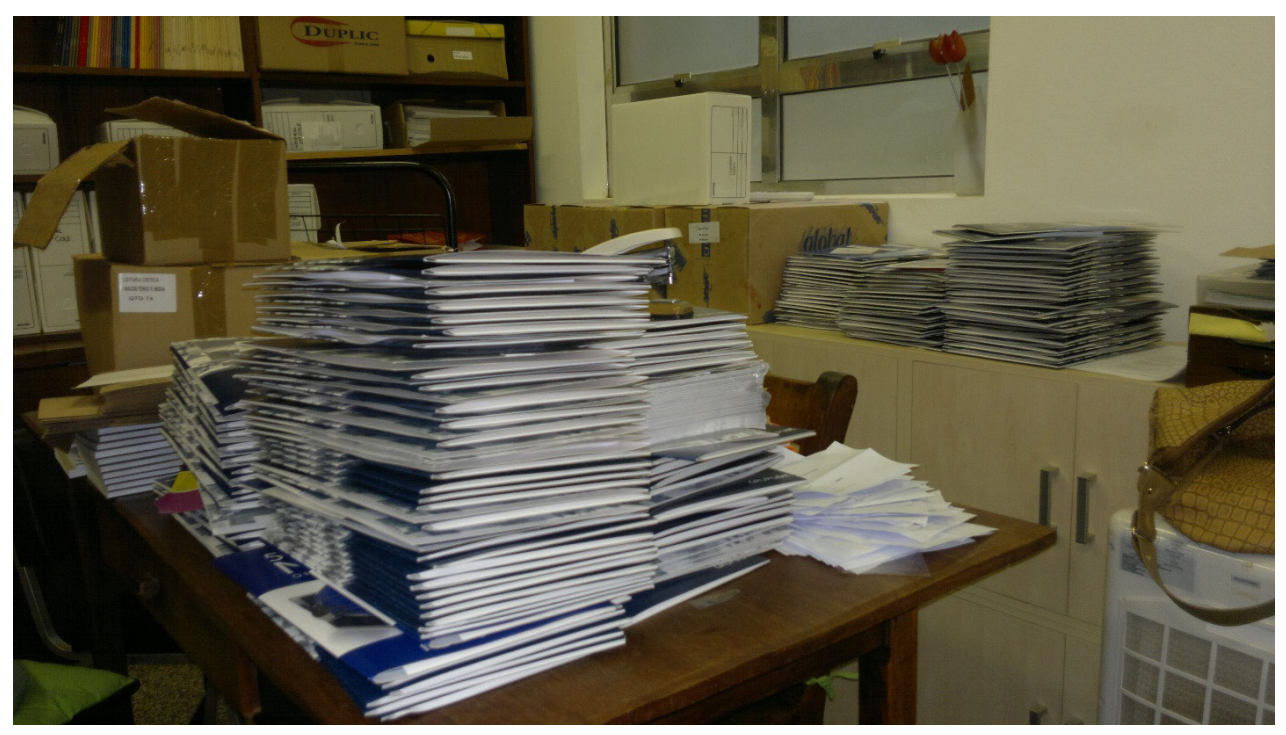

Fotografia 6 - Mesa de reuniões

A mesa. Ela é também suporte para papeis a serem assinados, lidos; para anotações de reuniões; para cadernos de brochuras que registram a discussão e os consensos (são esses cadernos que uso como muletas de minha memória, hoje). Em tempos de correio, ela é suporte para colagem de etiquetas, para carimbos. Em tempos de promoção de eventos, ela é suporte para a organização de panfletos de divulgação, de montagem de pastas etc.

Mas, em tempos de acolhimento, ela é suporte de café, às vezes com pão de queijo, para "tapear" a fome no avançar das horas; às vezes, de bolo em comemoração a aniversários. Relações de amizade, acadêmicas, institucionais etc., que tornam o desafio mais coletivo, produtivo e menos difícil.

Essa mesa tem ao seu redor os armários, que nos dão um pertecimento nessa entidade: eles estão cheios de exemplares de CDs, livros e revistas - publicações coordenadas ou de autoria de membros da diretoria ou daqueles que por ali passaram e que com a entidade estabeleceram relações. Os armários estão cheios de documentos que 
guardam a memória da entidade (cartas ou fichas de associados, recortes de matérias jornalísticas sobre a ALB, fita cassete com a voz de Paulo Freire e de outros intelectuais nacionais e internacionais ligados ao campo da leitura e da educação). Guardam kits com o material de cada evento: a camiseta, a sacola, o pôster, os anais, o folder, os brindes etc. Guardam fotos, fitas, disquetes e filmes que gravaram instantes mais públicos da entidade: um ginásio da Unicamp lotado nas aberturas ou conferências dos COLEs, uma sala de comunicação com apresentação de trabalhos de congressistas; imagens dos monitores nos últimos preparativos para a realização de um evento. Mais do que dispostos por uma estética na decoração, os objetos ali expostos e ali guardados falam à nossa alma e dão sentidos à entidade. São livros e revistas comercializados, são impressos e em forma de CDs, que alimentam o debate em torno da leitura e do livro, são publicações que sedimentam nossa postura política.

Esse fazer ordinário, miúdo, um tanto burocrático que marca o cotidiano de uma entidade, nem sempre visível e valorizado pelas avaliações externas (Qualis), ou para os associados ou participantes de seus eventos - é vivido por ex-membros das diretorias da ALB, por colegas das universidades, orientandos, alunos da graduação, professores do ensino fundamental e médio, pessoas contratadas que se juntam aos "voluntários" e que, por sua vez, se juntam aos funcionários da $\mathrm{FE}$, misturados na relação histórica entre a Faculdade e a ALB - nesses trinta anos. É uma fazer duro, inventivo, camarada, que em sua maioria, fica identificado no coletivo, no anonimato. É um fazer que permite construir relações de amizade, acadêmicas, institucionais etc., e que nos enraíza no mundo e nos dá sensação de pertencimento a uma comunidade, a um lugar, ao qual eu me orgulho de pertencer. Obrigada e parabéns, ALB, pelos seus 30 anos! 